\title{
Avaliação e disponibilidade de imóveis rurais na microrregião do Brejo Paraibano
}

\author{
Evaluation and availability of rural properties in the Brejo Paraibano microregion \\ Evaluación y disponibilidad de propiedades rurales en la microrregión Brejo
}

\section{Resumo}

A propriedade rural tem essa denominação pois quem vive nesse imóvel vive do que porduz, seja para seu próprio consumo ou para comercio, independentemente do volume de, vive-se especificamente da exploração da terra. $\mathrm{O}$ objetivo com esse trabalho foi apresentar os preços e hectares de propriedades destinadas à venda, sem o uso de critérios técnicos, adotando apenas os métodos de avaliação visual. O estudo foi desenvolvido em Pilões, Bananeiras e Areia, que pertencente à Microrregião do Brejo Paraibano. A coleta de dados foi feita mediante questionários semiestruturados, que continham questões sobre as formas de avaliação do valor do imóvel, e quais atributos poderiam alterar o possível valor de venda das propriedades, os mesmos foram aplicados com agricultores da zona rural. Observamos que das dez propriedades que encontram-se à venda nas três cidades consultadas no Brejo Paraibano, $60 \%$ estão sendo vendidas por corretores credenciados no CRECI/PB, e $40 \%$ não possui credenciamento. A venda de propriedades rurais nos municípios de Areia, Bananeiras e Pilões é feita através de avaliação do valor fixado para a propriedade, não segue um padrão preestabelecido, entretanto são utilizados métodos como: água, vegetação e construções tradicionais para avaliar a propriedade.

Palavras-chave: CRECI; Família; Imóvel rural; Valor da terra.

\begin{abstract}
The rural property has this name because those who live in that property live on what theyproduce, whether for their own consumption or for trade, regardless of the size of their production, live specifically from the exploitation of the land. The objective of this work was to present the evaluation methods for the purchase and sale of small rural
\end{abstract}


properties, without the use of technical criteria, adopting only the methods of visual and empirical evaluation. The study was carried out in Pilões, Bananeiras and Areia, which belongs to the Brejo Paraibano Microregion. For data collection, semi-structured questionnaires were elaborated and applied, which contained questions about the ways of evaluating the property value, and which attributes could alter the possible purchase and sale value of the properties, they were applied with farmers from the rural zone We note that of the ten properties that are for sale in the three cities consulted in Brejo Paraibano, 60\% are being sold by brokers accredited in CRECI / PB, and 40\% have no accreditation. The purchase and sale of rural properties in the municipalities of Areia, Bananeiras and Pilões takes place in a holistic way, and the evaluation of the fixed value of the property does not follow any standard norm or preestablished criteria of evaluation, however traditional methods are used to evaluate and quantify the property of interest, water, vegetation and buildings are a big differentiator when choosing a property as well, as the value attributed to it.

Keywords: CRECI; Family. Rural property; Land value.

\begin{abstract}
Resumen
La propiedad rural tiene este nombre porque quienes viven en esa propiedad viven de lo que producen, ya sea para su propio consumo o para el comercio, sin importar el tamaño de su producción, viven específicamente de la explotación de la tierra. El objetivo de este trabajo fue presentar los métodos de evaluación para la compra y venta de pequeñas propiedades rurales, sin el uso de criterios técnicos, adoptando únicamente los métodos de evaluación visual y empírica. El estudio se realizó en Pilões, Bananeiras y Areia, que pertenece a la Microrregión Brejo Paraibano. Para la recolección de datos se elaboraron y aplicaron cuestionarios semiestructurados, los cuales contenían preguntas sobre las formas de evaluar el valor de la propiedad, y qué atributos podrían alterar el posible valor de compra y venta de las propiedades, se aplicaron con agricultores de la zona rural. Nótese que de las diez propiedades que están a la venta en las tres ciudades consultadas en Brejo Paraibano, el $60 \%$ están siendo vendidas por corredores acreditados en CRECI / $\mathrm{PB}$, y el $40 \%$ no tienen acreditación. La compra y venta de fincas rústicas en los municipios de Areia, Bananeiras y Pilões se realiza de manera integral, y la evaluación del valor fijo de la propiedad no sigue ninguna norma estándar o criterio de evaluación preestablecido, sin embargo métodos tradicionales. se utilizan para evaluar y cuantificar la propiedad de interés, el agua, la vegetación y los edificios son un gran diferenciador a la hora de elegir una propiedad, así como el valor que se le atribuye.
\end{abstract}

Palabras clave: CRECI; Familia; Propiedad rural; Precio del terreno.

\title{
1. Introdução
}

A área da engenharia que reúne vários conhecimentos na área de engenharia e arquitetura é a engenharia de avaliações é uma especialidade, bem como em outras áreas das ciências sociais, exatas e da natureza, com o objetivo de determinar tecnicamente o valor de um bem (Uberti, 2006). As avaliações devem ser realizadas com base em normas técnicas da ABNT Associação brasileira de normas técnicas, através da aplicação de metodologia apropriada. A sua aplicação adequada exige, além dos conhecimentos necessários para elaboração do trabalho, dedicação, segurança, reserva, consciência, sendo de justiça, ética profissional, isenção, competência, senso crítico, investigação, observação, criatividade e, acima de tudo, amor.

A NBR 14653-1 auxilia na determinação do valor de um bem, ou seja, no seu valor de mercado, sendo que o valor de mercado é a quantia mais provável pela qual se negociaria um bem, numa data de referência, dentro das condições do mercado vigente. Valor de um bem decorre sempre de sua utilidade, entendida esta como a sua capacidade de atender a uma necessidade, a um desejo, e até mesmo a um capricho (Moreira, 1994). Para o mesmo autor, a palavra valor é usada em muitos sentidos diferentes. Quando aplicado a propriedade, traz consigo um sentido de desejo, de posse, domínio ou troca de propriedade, medida em termos de unidade imobiliária. O valor de um bem imóvel, a exemplo de outros bens de consumo, também é determinado pela lei da oferta e da procura, que estabelece que quanto maior a necessidade, maior a procura e maior o valor. E, quanto menor a quantidade de bens disponíveis no mercado, maior a raridade e maior seu valor. O valor de um imóvel é então, função da utilidade e da escassez.

A aplicação da metodologia mais adequada para realização de um trabalho avaliatório depende fundamentalmente das condições mercadológicas com se defronta o avaliador, pelas informações coletadas neste mercado, bem como pela natureza do serviço que pretende desenvolver. Os métodos disponíveis, de acordo com a NBR 14653- 1, classificam-se em métodos 
para identificar o valor de um bem, de seus frutos e direitos e métodos para identificar o custo de um bem, podendo ser, em determinadas circunstâncias, conjugados. Cada um destes métodos será estudado posteriormente (Hohheim, 2002).

Com o crescimento populacional, grandes empreendimentos necessitam ser feitos para garantir o atendimento das necessidades básicas do homem e uma melhor organização populacional. Com esse crescimento as áreas rurais, são os principais alvos para a expansão opulacional. Com esse crescimento as áreas rurais, são os principais alvos para a expansão populacional. E esse crescimento faz com que ocorra processos de desapropriação e uma grande discussão sobre a correta avaliação dos imóveis rurais (Breder, 2013).

Em um imóvel rural tudo gira em torno da exploração agropastoril, e deve-se observar, avaliar e qualificar suas terras em torno de sua exploração, da sua qualidade e exploração, deixando de lado o preconceito que nossos olhos enxergam ao ver uma estrada de terra, uma montanha, um morro, uma vársea, uma área alagada. O que é bom ou ruim, dependerá do aproveitamento e da qualidade da exploração que o produtor adaptou a sua terra (Breder 2013). A Microrregião do Brejo Paraibano, formada por oito municípios (Alagoa Grande, Alagoa Nova, Areia, Bananeiras, Borborema, Pilões e Serraria), apresenta relevo e posição geográfica que contribuem para a ocorrência de clima úmido, com temperaturas amenas e pluviosidade média anual em torno de 1500 a 1800 milímetros, solos férteis, hidrografia perene e condições favoráveis ao desenvolvimento da agricultura (Moreira \& Targino, 1997).

Atualmente os estudos que procuram investigar as mudanças no meio rural têm abandonado o enfoque dos tradicionais setores econômicos e avançado para uma abordagem territorial no desenvolvimento local, considerando também os efeitos da pluriatividade em seus avanços ou retrocessos (Ortega, 2015; Sousa \& Pereira, 2016). O objetivo com esse trabalho foi apresentar os preços e hectares de propriedades destinadas à venda, sem o uso de critérios técnicos, adotando apenas os métodos de avaliação visual.

\section{Material e Métodos}

\subsection{Local de coleta}

O estudo foi desenvolvido em Pilões, Bananeiras e Areia, que pertencente à Microrregião do Brejo Paraibano. O brejo paraibano é caracterizado por ser uma área que apresenta um maior índice pluviométrico, quando comparado com as demais microrregiões que compõem o estado da Paraíba, sem incluir o litoral, portanto é uma região que possui grande potencial produtivo. Sua população foi estimada em 116.437 habitantes (IBGE 2015), está dividida em oito municípios e possui uma área total de 1.202,1 km². A região do Brejo situada próximo ao litoral paraibano apresenta características e regime climático semelhante ao litoral, porém, com índice pluviométrico bem abaixo da ordem 1200 mm anuais. 
Figura 1. Localização do brejo paraibano.

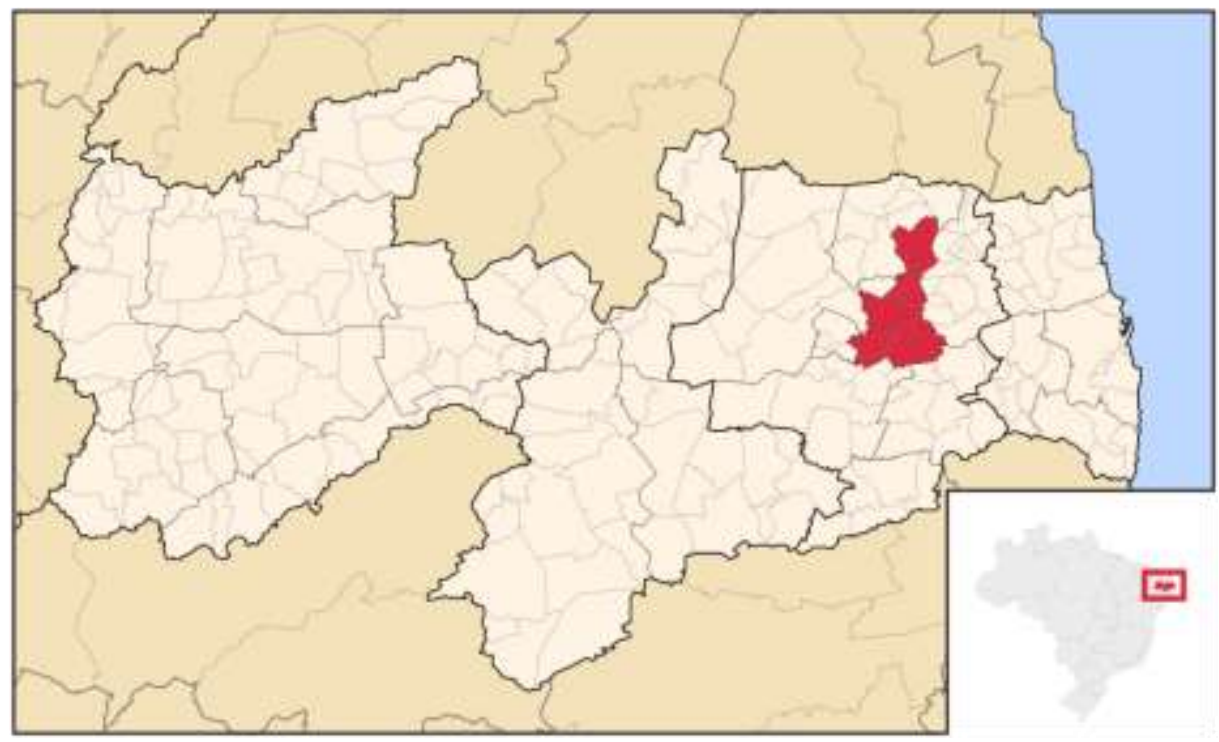

Fonte: Google Maps (2021).

Segundo o IBGE (2010), o município de Bananeiras, objeto desta pesquisa, está localizado na Mesorregião do Agreste Paraibano e na Microrregião do Brejo Paraibano. Sua população é de 21.851 habitantes, distribuída em uma área de $258 \mathrm{~km}^{2}$, apresentando uma densidade demográfica de 84,72 hab. $/ \mathrm{km}^{2}$. Seu Índice de Desenvolvimento Humano (IDH) é de 0.599, segundo o Atlas de Desenvolvimento Humano/PNUD (2000). A incidência de pobreza ou, de maneira mais direta, a sua taxa de pobreza é de $58,12 \%$, ou seja, mais da metade da população vive em condições precárias.

No censo Agrário de 2017, realizado pelo IBGE em Areia, a cana-de-açúcar se destaca na produção agrícola. O município conta com 92 estabelecimentos voltados para a produção da cana, sendo produzidas 32.155,573 toneladas, colhidas em uma área de 818.727 hectares. Atualmente, o ramo do turismo tem crescido significativamente em Areia, tanto pela condição de cidade tombada, como pelos atrativos naturais, como trilhas ecológicas, cachoeiras, passeios de lanchas na barragem Saulo Maia (barragem que atualmente abastece a cidade e várias cidades circunvizinhas), além de ambientes particulares, como restaurantes, hotéis, pousadas e os engenhos.

O município de Pilões apresenta vários rios perenes, belas cachoeiras e pequenos córregos que compõem a bacia hidrográfica do Rio Mamanguape, com vestígios remanescentes da Mata Atlântica, apresenta vegetação formada por Florestas Subcaducifólica e Caducifólica, próprias das áreas agrestes. Baseou sua economia, durante muito tempo, no plantio da canade-açúcar para a produção da rapadura e da cachaça. A produção da banana, do urucum, da castanha de caju, da mandioca, e a criação de rebanhos bovinos e caprinos são as atuais fontes da economia local. A produção de flores é o mais novo elemento da economia pilonense (IBGE, 2017).

\subsection{Questionário}

Com base em Silva e Menezes (2005), a natureza da pesquisa será considerada como aplicada, pois, tem a finalidade de reunir conhecimentos para resolver problemas por meio de estudos dirigidos e aplicações práticas. O estudo perpassará pela abordagem quantitativa e qualitativa. Na coleta de dados utilizamos questionários semiestruturados, que continham questões sobre as formas de avaliação do valor do imóvel, e quais atributos poderiam alterar o possível valor de venda das propriedades. Estes questionários foram aplicados através de um diálogo informal com um total de 10 famílias. 


\subsection{Análise dos dados}

Na fase de preparação dos dados, entendeu-se a atribuição dos dados, para isso foi utilizada uma planilha do Excel, para visualizar as tabelas. Após organizar o conjunto de dados na planilha, prosseguiu-se com a preparação dos dados, notadamente consistência dos dados, verificação da existência de valores faltantes, seleção dos atributos mais relevantes e a possibilidade da aplicação de procedimentos para balanceamentos de classes.

\section{Resultados e Discussão}

As perguntas dos questionários nos auxiliam a avaliação de bem feitorias presentes na propriedade o que fazem agregar valor ao imóvel. As cercas, casas, currais e galpões construídos acrescem valor, pois dessa forma os novos donos terão menores gastos com a propriedade, pastos e culturas valorizam a terra. A presença de água, matas e capoeiras aumentam o valor a terra, já que a água presente na propriedade permite o seu uso e facilita a implantação de culturas e criações, já a presença de matas e capoeiras permite o uso da área de formas diversas, além de agregar valor por possíveis espécies florestais presentes no local (Silva et al., 2018).

As construções precisam de investimento e da mão de obra do trabalhador ao longo do tempo, o mesmo utiliza estes pontos para agregar valor à propriedade. Alguns critérios não são adotados para avaliar as potencialidades, como a análise da qualidade do solo e a presença de relevos ou depressões topográficas na área. Segundo as respostas a falta de assistência técnica e o alto valor a ser pago a um profissional, torna mais difícil o acesso a informações concretas, que possam ajudar os proprietários a tabelar um valor justo a ser oferecido para a propriedade situação observada por Silva t al. (2018) em sua pesquisa.

Na Tabela 1 observa-se a diferença entre os valores de compra e os valores especulados para possíveis vendas dos imóveis. Observamos que das dez propriedades que encontram-se à venda nas três cidades consultadas no Brejo Paraibano, 60 \% estão sendo vendidas por corretores credenciados no CRECI/PB, e 40 \% não possui credenciamento. Existem mais sítios e chácaras para vender do que terrenos, sítios e fazendas. Os sítios e chácaras que estão à venda em Areia não são anunciados por corretores, já em Bananeiras são anunciados por corretores.

Tabela 1. Tamanho e valor de propriedades anunciadas ou não por corretores credenciados no CRECI/PB.

\begin{tabular}{llccc}
\hline Localidade & $\begin{array}{l}\text { Categoria } \\
\text { propriedade }\end{array}$ & $\begin{array}{c}\text { da } \\
\text { Anunciado por } \\
\text { corretor } \\
\text { registrado no } \\
\text { CRECI/PB }\end{array}$ & $\begin{array}{c}\text { Área da } \\
\text { propriedade em } \\
\text { hectares }\end{array}$ & $\begin{array}{c}\text { Valor pedido no } \\
\text { anúncio (R\$) }\end{array}$ \\
\hline \multirow{3}{*}{ Areia } & Terrenos, sítios e & Sim & 14,0 & $750.000,00$ \\
& fazendas & Não & 5,5 & $225.000,00$ \\
& Sítio / Chácara & Não & 1,0 & $100.000,00$ \\
\hline \multirow{3}{*}{ Bananeiras } & Terrenos, sítios e & Sim & 3,0 & $250.000,00$ \\
& fazendas & Não & 18,0 & $1.200,000$ \\
& Sítio / Chácara & Sim & 1,0 & $110.000,00$ \\
& & Sim & 2,85 & $110.000,00$ \\
\multirow{3}{*}{ Pilões } & Sim & 1,5 & $350.000,00$ \\
\hline & Sítio / Chácara & Não & 1,0 & $230.000,00$ \\
& Terrenos, sítios e & Sim & 165,0 & $3.500,000$ \\
\hline
\end{tabular}

Fonte: CRECI/PB. Autores. 
Considerando por cidade observamos na Figura 2 que em Areia aproximadamente 67\% dos corretores que estão ligados à venda das três propriedades na possuem credenciamento, já em Bananeiras $80 \%$ possui credenciamento e em Pilões $50 \%$.

Figura 2. Corretores credenciados no CRECI/PB por cidade do Brejo Paraibano.

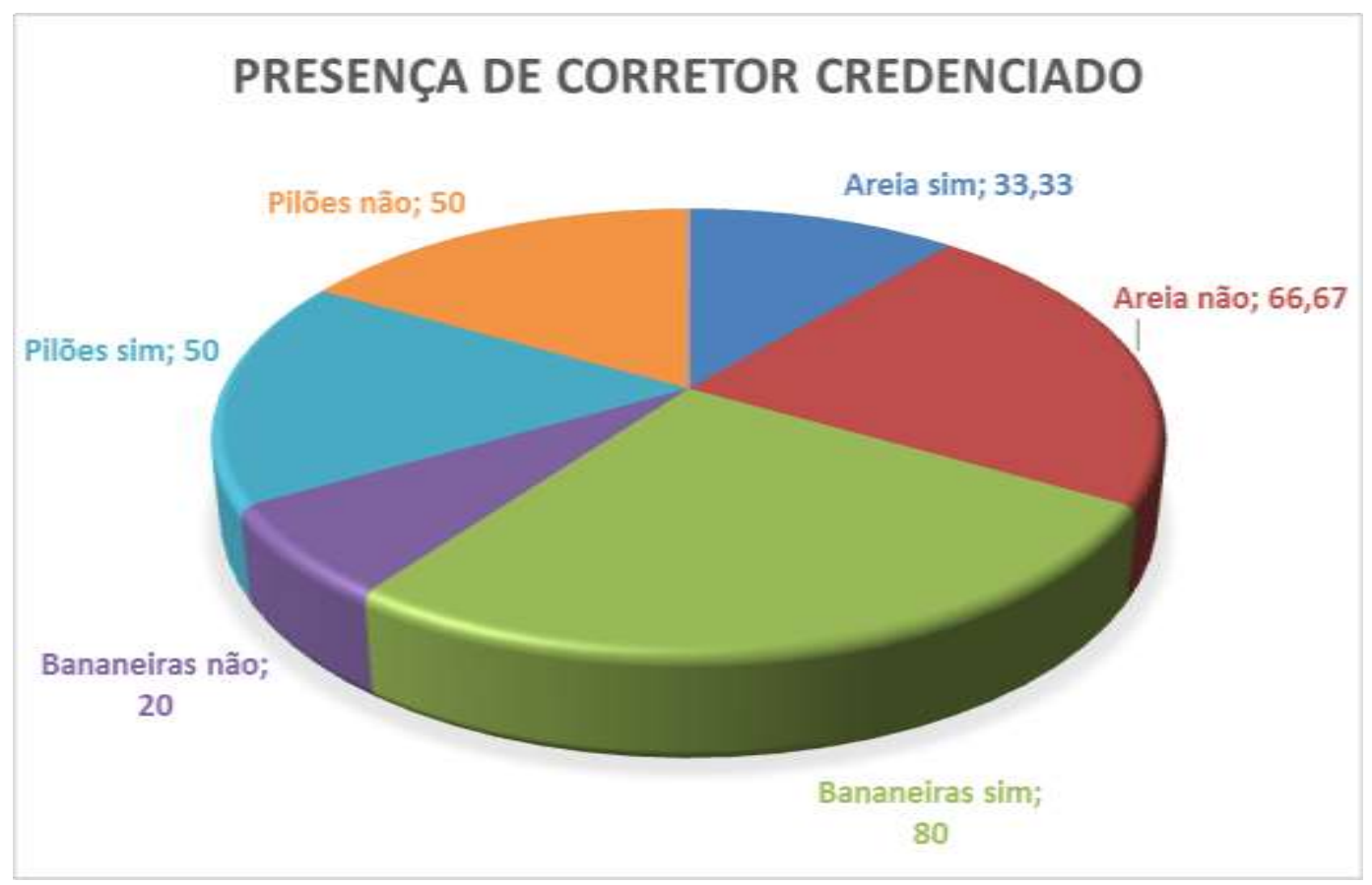

Fonte: CRECI/PB. Autores.

O CRECI é um certificado que garante que o profissional está exercendo a profissão da maneira correta, dentro da lei de forma ética, em âmbitos sociais, econômicos e políticos. O corretor de imóveis, no exercício de sua função, presta assessoria às partes interessadas, tornando a transação livre e desembaraçada de ônus, encargos, litígios e taxas ou impostos atrasados. É sua função, também, intervir nos contratos de compra e venda de imóveis, permutas, promessas de venda, cessões de direitos e, em se tratando de administração de imóveis, seus serviços se estendem às incorporações, hipotecas, financiamentos, loteamentos, locações e administração de bens (Palhares, 2006).

A importância do corretor de imóveis é tão grande que a profissão é regulamentada pela Lei n ${ }^{\circ}$ 6.530/78, ou seja, somente profissionais legalmente habilitados e regularmente inscritos no conselho profissional correspondente podem exercêla. A diferenciação espacial e a diversificação geoeconômica estadual, o Plano de Desenvolvimento Sustentável do Estado da Paraíba, estabeleceu, dentre as diretrizes para a reorganização do seu espaço sócio-econômico, ações programadas para promover a reestruturação e fortalecimento da economia do Brejo, incluindo a seleção de alternativas para a exploração agrícola e agroindustrial (SEPLAN, 1996). Passados 20 anos, pode-se constatar no Brejo Paraibano, mudanças nas estruturas de apoio ao desenvolvimento municipal, no surgimento de novos espaços imobiliários, no conjunto de novas atividades rurais, nos índices de desenvolvimento sustentável, mas uma parcela considerável de sua população ainda está enredada na pobreza e na exclusão social (Sousa \& Pereira, 2016).

Com o crescimento populaciona as áreas consideradas rurais, são os principais alvos para a expansão populacional. E esse crescimento trás grandes processos de desapropriação e uma grande discussão sobre a correta avaliação dos imóveis rurais (Breder, 2013). Observa-se uma variação no preço do hectare das propriedades nas três cidades analisadas. Na cidade de Areia 
o valor varia de 53.571,4286 até 100.000,000 R\$, Já em Bananeiras o valor varia de 38.596,49 a 233.333,33 R\$ em Pilões o valor varia de $21.212,12$ a $230.000,00 \mathrm{R} \$$.

Comprando o preço do hectare de três propriedades de cada cidade que possui apenas 1 hectare (Figura 3) observamos que o hectare mais caro está em Pilões, sendo 51\% mais caro do que nas outras duas cidades. A cidade do município de Areia com 1 hectare não possui corretor a de Bananeiras possui corretor e é mais barata do que a de Areia, a de Pilões não possui corretor e é a mais cara.

Figura 3. Porcentagem do preço por hectare nos municípios.

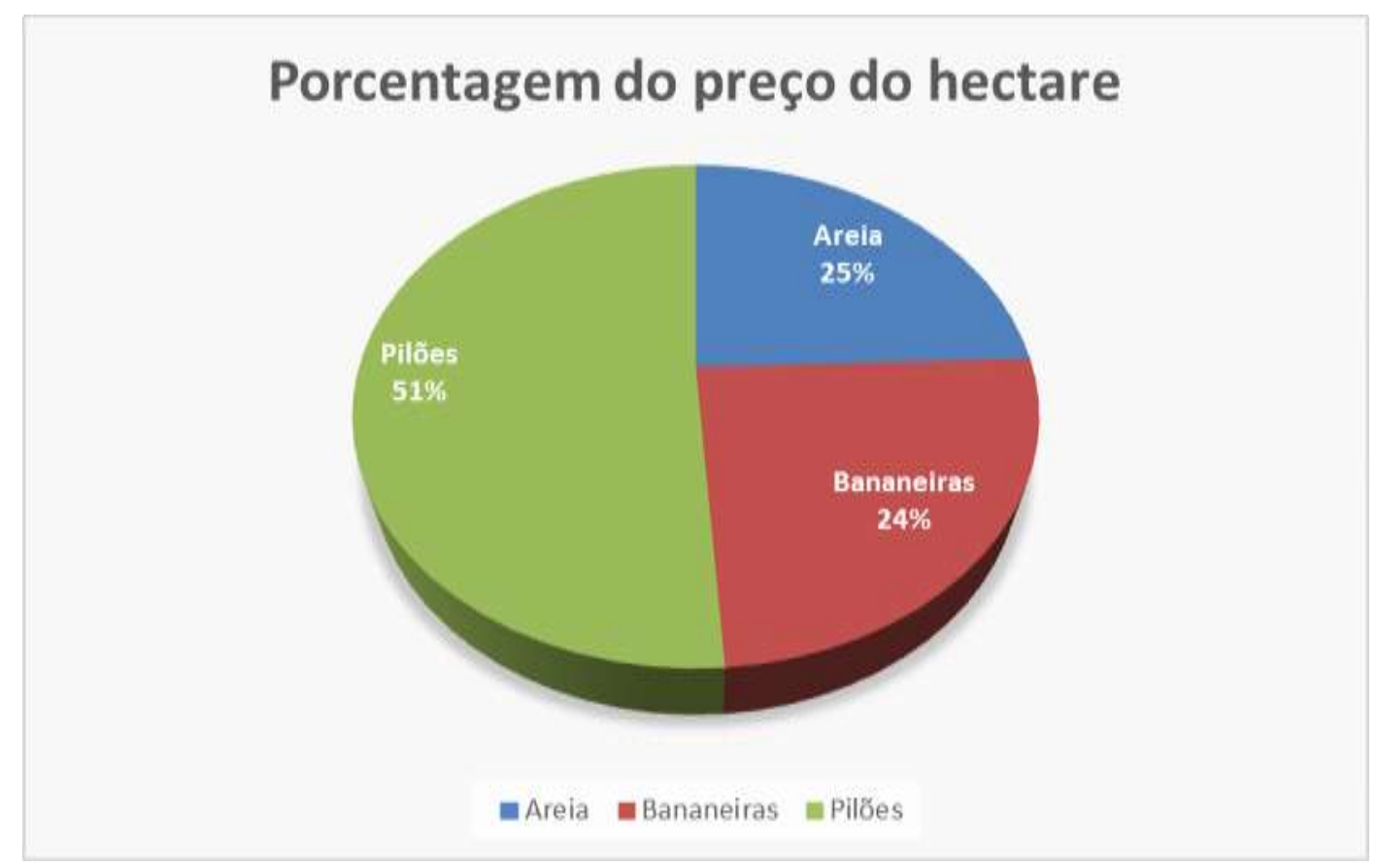

Fonte: CRECI/PB. Autores.

De acordo com Silva et al. (2018) as terras são os principais componentes de um imóvel rural e são avaliadas em função de sua capacidade de uso e localização, porém sem vegetação e sem benfeitorias, dentro do conceito terra nua. Na Figura 4 temos a variação média de preço com e sem o corretor nas cidades avaliadas, na cidade de Areia a variação de preço é de $22 \%$ positiva com o corretor, no caso de sem corretor é de 12\%, em Bananeiras é de $34 \%$ e $19 \%$ com e sem corretor, respectivamente. Já em Pilões o valor varia de 7 e $6 \%$ com e sem corretor, respectivamente. Quando se avalia um imóvel rural, o avaliador se orientará pela NBR 14.653-3, que classifica os imóveis rurais. Mas sempre haverá uma situação onde o avaliador terá que interpretar e se orientar pele motivo da avaliação, para que consiga avaliar o bem da melhor e mais completa forma. As avaliações baseiam-se em pesquisas de preços de imóveis, culturas e benfeitorias realizadas na região dos empreendimentos. As avaliações são realizadas seguindo a NBR 14.653 de 2004 orientam para os procedimentos gerais e detalhamento para imóveis urbanos e rurais. 
Figura 4. Preço médio do hectare por cidade com e sem corretor.

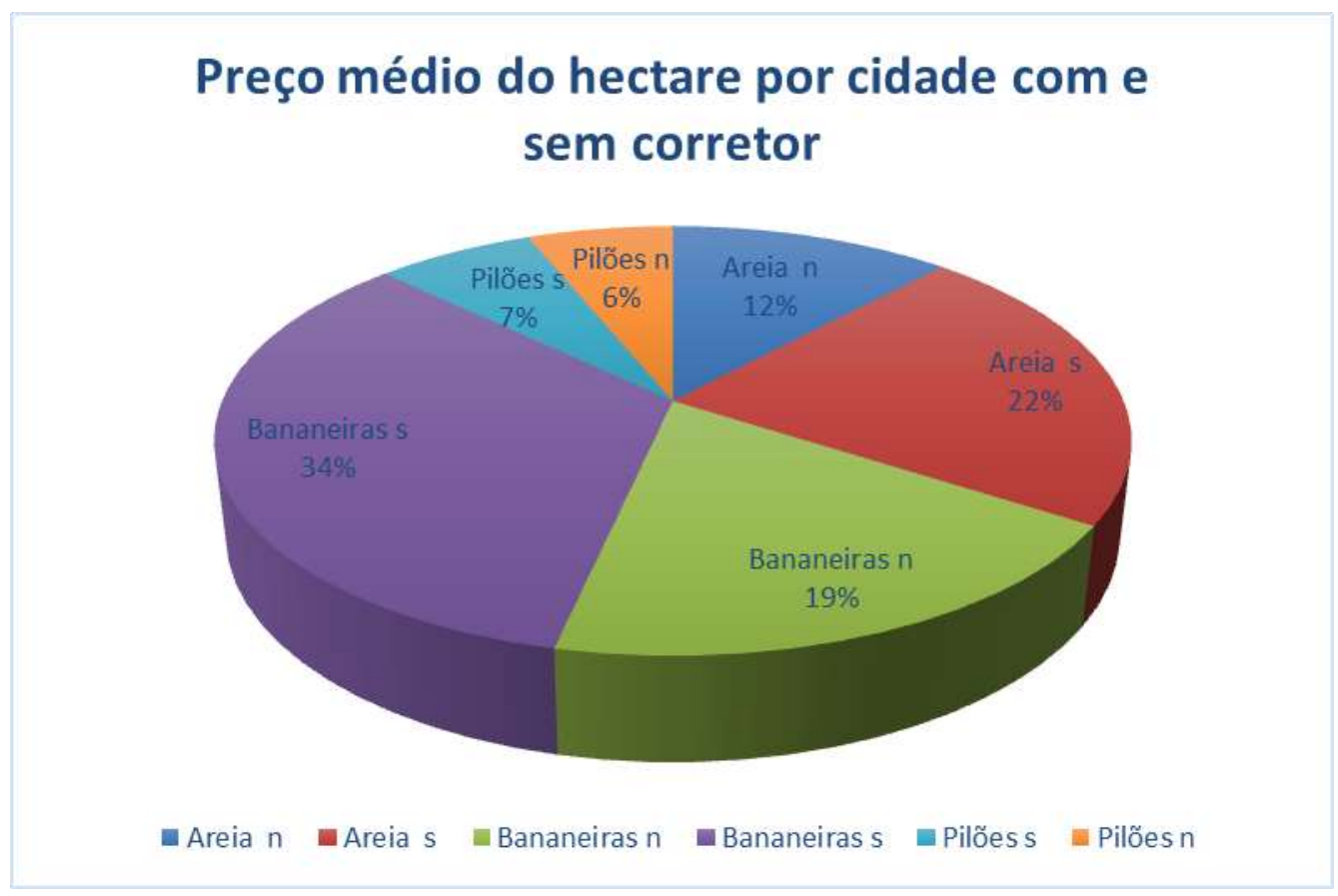

Fonte: CRECI/PB. Autores.

Quando o terreno é vendido por um corretor o preço é mais alto. Em Bananeiras, dependendo da localização, em média um lote simples medindo 10x25m gira em torno de R\$20.000,00 a 25.000,00 (loteamentos externos). Já um terreno localizado dentro de um condomínio fechado, medindo 15x30m, apresenta um preço de $\mathrm{R} \$ 40.000,00$ em média. Por fim, uma casa construída dentro de um condomínio fechado (modelo chalé), pode ser adquirida por cerca de R\$200.000,00. Algumas chegam a valer muito mais, conforme relatou um dos corretores (Silva, 2012).

Desde 2005, após a publicação da Lei municipal nº 313, os empreendimentos se multiplicaram por todo o município, tanto na zona urbana quanto zona rural. Segundo informações do Departamento de Administração Tributária do município de Bananeiras (2012), entre 2005 e junho deste ano registrou-se 16 empreendimentos imobiliários no município, sendo nove (9) condomínios residências horizontais e sete (7) loteamentos, totalizando 3.335 lotes com mais de 487 novas construções.

O PIB de Areia é de 10.249,84, o de Bananeiras é de 11.279,55 e o de Pilões é de 11.447, 82 (IBGE, 2020) o PIB é um dos fatores que viabiliza a aferição das atividades econômicas por meio de levantamentos dos bens e serviços produzidos no país. A partir do ranking do município de Areia, alguns dados merecem especial destaque. De acordo com o IBGE em 2013 Areia ocupava a $31^{\mathrm{a}}$ posição, tendo um crescimento de 15,4\% em relação ao período anterior (Breder, 2013).

Souza e Pereira (2016), em seu trabalho observam que a microrregião do Brejo Paraibano tem forte participação na economia da Paraíba, pois essa microrregião é localizada geograficamente, de modo que favoreça a produção, principalmente, da cana de açúcar e da banana, segundo os dados do Instituto Brasileiro de Geografia e Estatísticas (IBGE) nos anos de 2004 a 2013. Desse modo, esse posicionamento geográfico acaba apresentando aspecto locacional favorável para uma agricultura mais desenvolvida. A conclusão é que as culturas temporárias e permanentes do Brejo Paraibano com destaques para os produtos citados acima, afetam positivamente a produção agrícola da Paraíba.

Quando se trata da avaliação de bens imóveis, deve-se levar em consideração diversos fatores que lhes dá propriedade, tais como: distribuição espacial, seus usos, características físicas, valorização e aceitação no mercado, levando em conta que com o crescimento de uma cidade é comum a alteração espontânea e significativa do perfil ocupacional de determinadas regiões e bairros, devendo assim o profissional de avaliações estar atento a essas transformações (Lima, 2012). 
Segundo Lima (2016), é perfeitamente possível a utilização de outro sistema de classificação de terras, com a finalidade da engenharia de avaliações de imóveis rurais, a exemplo do uso da aptidão agrícola, sendo necessário o desenvolvimento de todo o procedimento estatístico.

\section{Considerações Finais}

A venda de propriedades rurais nos municípios de Areia, Bananeiras e Pilões é feita através de avaliação do valor fixado para a propriedade, não segue um padrão preestabelecido, entretanto são utilizados métodos como: água, vegetação e construções tradicionais para avaliar a propriedade.

\section{Agradecimentos}

Agradeço ao Conselho Nacional de Desenvolvimento Científico e Tecnológico (Cnpq) - Brasil pela de concessão de bolsa PIBIC.

\section{Referências}

ABNT - Associação Brasileira de Normas Técnicas. (2004). BR 14653:1 - Avaliação de bens Parte 1: Procedimentos gerais.

Breder, J. P (2013) Avaliação de imóveis rurais. (Curso de Especialização em Construção Civil) Universidade Federal de Minas Gerais. 50 pág.

Hochheim, N. (2002). Engenharia de Avaliações II (Apostila). Universidade Federal de Santa Catarina.

Instituto Brasileiro de Geografia e Estatística (IBGE). (2010). Mapa da pobreza e desigualdade. IBGE, 2003. http://www.ibge.gov.br/home/presidencia/n oticias/noticia_visualiza.php?id_noticia=1293\&id_pagina=1.

IBGE - Instituto Brasileiro de Geografia e Estatística . (2015). http://www.ibge.gov.br/cidadesat/xtras/temas.php?codmun=313120\&idtema=9 $8 \&$ search=mina s-gerais|ipanema|pecuaria-2011).

IBGE, Instituto Brasileiro de Geografia e Estatística. (2017). Brasil em Síntese. https://cidades.ibge.gov.br/brasil/pb/areia/panorama.

Lima, A. S. D. (2012). Desenvolvimento de um laudo de avaliação de um imóvel residencial multifamiliar localizado no bairro do bessa, na cidade de João Pessoa - PB. Monografia.

Lima, M. R. C. (2016). Engenharia de avaliações aplicada em propriedades rurais. IBAPE. 267p

Moreira, A. L. (1994). Princípios de engenharia de avaliações. Pini.

Moreira, E., \& Targino, I. (1997). Capítulos de Geografia Agrária da Paraíba. Editora Universitária / UFPB 332 p.

Ortega, A. C. (Org.). (2015). Territórios Políticas Públicas e Estratégias de Desenvolvimento. Editora Alínea, 220 p.

Palhares, A. (2006). Desenvolvimento de conteúdo, mediação pedagógica e design gráfico. Monitor Editora (4a ed.), 222 pág.

SEPLAN -Secretaria do Planejamento do Estado da Paraíba. (2006). Plano de Desenvolvimento Sustentável - Versão Resumida para Discussão. 171 p.

Silva, D. A. C., Fontes, M. G. C., Oliveira, J. S., Coutinho, W. N., \& Costa, A. P. D. (2018). Análise dos métodos utilizados para avaliação de pequenos imóveis rurais no município de Irituia - PA. In: Congresso Internacional das Ciências Agrárias.

Silva, E. L., Menezes, E. M. (2005). Metodologia da pesquisa e elaboração de dissertação. 138. https://projetos.inf.ufsc.br/arquivos/Metodologia_de_pesqu isa_e_elaboracao_de_teses_e_diss ertacoes_4ed.pdf.

Sousa, D. S., \& Pereira, W. E. (2016). Atividade agrícola do brejo paraibano: declínio e tendências atuais. Revista Brasileira de Agropecuária Sustentável, $6(3), 11-20$

Uberti, M. S. (2006). Avaliações e perícias. http://www.ufrrj.br/institutos/it/deng/marlene/downloads/IT188\%20Avaliacao\%20e\%20pericias/Apost ila\%20IT\%20188.pdf. 